\title{
A Performance da Oralidade Docente
}

\author{
The Performance of Teaching Speaking
}

\author{
Gilberto Icle* \\ Universidade Federal do Rlo Grande do Sul \\ Márcia Pessoa Dal Belo** \\ Universidade Federal do Rio Grande do Sul
}

Resumo Este texto apresenta a oralidade docente como performance, apoiandose em diferentes autores para caracterizar o trabalho dos professores de teatro. Utiliza-se do trabalho de Stanislavski para exemplificar as situações entre ator e professor. Discute-se, com efeito, a centralidade da oralidade como conteúdo e como método próprio do trabalho teatral. Problematiza-se, assim, a oralidade do professor como instrumento por intermédio do qual o professor poetiza sua própria voz, tornando-a veículo do trabalho pedagógico. Este texto apoia-se, especialmente, em Bauman, Zumthor e Schechner para circunscrever a oralidade docente como temática central da didática teatral. Defende-se a possibilidade de pensar a tarefa pedagógica em teatro como ato de performance oral.

PALAVRAS-ChaVE: Performance, docência, Educação.

Abstract This text presents the orality as performance faculty, drawing on different authors to characterize the work of teachers. It uses Stanislavski's work to exemplify the situations between actor and professor. It discusses the centrality of orality as content and as a method of the theatrical work. Thus, discusses the orality of the professor as an instrument through which the teacher makes his own voice a poem, making it the vehicle of pedagogical work. This text relies especially on Bauman, Zumthor and Schechner to circumscribe the orality as central theme teaching didactics theatrical. This paper advocates the possibility of thinking the pedagogical task in theater as an act of oral performance.

KEYWORDS: Performance, teaching, Education. 
A performance da oralidade teatral nas práticas docentes em teatro é um tema extremamente relevante, considerando a importância que a emissão vocal tem para o trabalho do ator, bem como o papel que desempenha nos processos de ensino e aprendizagem. Como elemento constitutivo do trabalho do ator, ao menos da sua tradição no teatro euro-americano, a oralidade confunde-se com a própria natureza do teatro e do trabalho do ator. No entanto, neste texto, trataremos não apenas da oralidade como elemento a ser desenvolvido pelo aluno ator, mas também, e, sobretudo, como os professores de teatro utilizam a oralidade como elemento performático para ensinar sobre oralidade.

O território das aulas de teatro será marcado, neste trabalho, pelos exemplos extraídos da Pedagogia do Ator de Konstantin Stanislavski, como fonte originária da qual emana os princípios da Pedagogia Teatral.

Este texto pretende, entrementes, pensar sobre a possibilidade de reconhecer no professor de teatro um performer que se utiliza da sua oralidade para poetizar didaticamente. A oralidade, com efeito, será tratada aqui como o ato de comunicar-se por intermédio da fala, ou seja, um procedimento verbal que resulta na transmissão oral, cujo som emitido pela comunicação oral é a voz. A palavra é tratada como uma unidade de sentidos formada pelos sons de uma língua, cuja função é representar partes do pensamento e, por isso, ela constitui uma unidade da linguagem humana. Entretanto, para além disso, circunscrevemos a palavra não apenas como expressão do pensamento, mas também na sua autonomia própria, como ação do pensamento.

\section{A oralidade como performance}

Bauman (1984) afirma que é necessário reconhecer que a arte verbal como performance é um recurso de comunicação disponível entre os membros de uma determinada comunidade e deve ser entendida como sendo uma espécie de comunicação localizada, ou seja, um modo de falar. O autor diz que na abordagem performativa, o manuseio formal das características linguísticas é secundário para a natureza da performance, uma vez que ela é concebida como um modo de comunicação. Ele aponta que na performance é instalado um quadro interpretativo dentro do qual as mensagens que estão sendo comunicadas devem ser entendidas e que esse quadro pode se contrapor aos sentidos de outro, ou seja, a interpretação não é literal. Bauman (1984) assinala que, "[...] fundamentalmente, a performance verbal é um modo de comunicação que consiste em assumir a responsabilidade por uma plateia" (BAUMAN, 1984, p. 11).

Dessa forma, para Bauman (1984), performance envolve do performer o compromisso de estabelecer a confiabilidade para com uma plateia, por meio da qual a comunicação é operada além do conteúdo referencial. Do ponto de vista da plateia, o ato de expressão por parte do performer é tido como objeto de avaliação pela maneira como esse ato é desenvolvido, pela habilidade relativa e pela efetividade do performer. $\mathrm{O}$ autor considera que "[...] a performance verbal atrai a atenção especial e acurada para o ato da expressão, conduz a plateia e concede intensidade ao trabalho do performer"(BAUMAN, 1984, p. 13). Ele observa que a implicação do conceito de performance para a teoria da arte verbal se reflete na não necessidade de começar com 
textos de arte plena, identificado por tradições formais, pois a performance está sob o domínio da arte verbal como comunicação falada.

Zumthor (2007), por sua vez, declara que seu interesse pela voz humana, ou pelas vozes, se deve ao fato delas serem, por natureza, particulares e concretas. Ele considera que "[...] a voz, na sua qualidade de emanação do corpo, o representa sonoramente e de forma plena" (ZUMTHOR, 2007, p. 27).

Desse modo, a inquestionável importância do papel da performance da oralidade para o trabalho do ator se sustenta no argumento de Zumthor quanto à natureza da performance que, para ele, tem o poder de afetar aquilo que é conhecido e, ao mesmo tempo, modificar o conhecimento, não sendo apenas um meio de comunicação, pois ao comunicar-se, ela o marca. Trata-se de "[...] um saber que implica e comanda uma presença e uma conduta, um Dasein comportando coordenadas espaço-temporais e físio-psíquicas concretas, uma ordem de valores encarnadas em um corpo vivo" (ZUMTHOR, 2007, p. 31). De acordo com esse autor

[...] a performance é, enquanto prática poética, o prolongamento de um esforço primordial para emancipar a linguagem de um tempo meramente biológico - tempo no qual ela se insere por força de sua função comunicativa e representativa; esforço que salva a linguagem do esquecimento e da destruição, pelo acolhimento, pela recepção no corpo, na escuta -dos sons e da imagens - daquilo que não encontra lugar numa palavra de uso meramente instrumental. (ZUMTHOR, 2007, p. 48)

Assim, tais concepções de performanceda oralidade e as portas que elas abrem para refinar a comunicação verbal, não há como não reconhecer uma docência performática ${ }^{1}$ como uma arte oral, como uma oralidade específica e integrante de um sistema docente que performatiza corpo e voz para cumprir seus fins.

\section{A centralidade da oralidade no trabalho teatral}

Fortuna (2000) considera que "[...] o ator vivifica em oralidade, a sacralidade escritural do autor" (FORTUNA, 2000, p. 17), uma vez que tem a prerrogativa de transformar um texto escrito insignificante, do ponto de vista de sua estrutura linguística, num discurso extraordinário e torná-lo emocionalmente empático, contundente, persuasivo e poético. A autora ressalta que exprimir-se oralmente no teatro é como reger uma orquestra, em que o ator é o maestro, o público, os instrumentos musicais e os demais elementos são suportes e acessórios. No processo de encenação, o ator irá lançar mão dos recursos da imaginação criadora para buscar possibilidades de interação com a plateia, entretanto Fortuna (2000) ressalta que “[...] para uma boa atuação é fundamental que ele use com destreza a própria capacidade vocal, explorando ao máximo as suas possibilidades" (FORTUNA, 2000, p. 17).

$\mathrm{Na}$ descrição da importância da voz no trabalho do ator, Icle e Alcântara (2012), mencionam que a voz deve ser pensada não apenas como expressão, como constituição de um aparato de habilidades técnicas, com o objetivo de fazer funcionar 
o aparelho vocal, visando uma comunicação eficaz em cena. Para os autores, a voz deve ser pensada, ainda, "[...] como um lócus e acontecimento corpóreo vocal, [...] antes de tudo uma experiência de voz, uma voz experiência, [...] na relação com o outro em cena" (ICLE; ALCÂNTARA,2012, p. 130).

Os autores defendem que a voz é mais do que uma extensão do corpo, ela é corpo, uma vez que se constitui de qualidades psicofísicas, as quais podem ser dimensionadas por características atribuídas ao corpo. Assim, eles propõem que o ator deve pensar a voz "[...] naquilo que transborda a expressão, que a ultrapassa, que vai além da simples expressão de significados" (ICLE, ALCÂNTARA, 2012, p. 132). Neste sentido, parece que todo o trabalho vocal com rigor técnico, emoção e qualidade na emissão do som resulta no maior de todos objetivos do teatro, na empatia com a plateia.

Stanislavski (1997), em sua pedagogia, dava grande ênfase à oralidade para o trabalho do ator e começou a resolver os problemas da expressividade da fala por um caminho próprio. Ele ressaltava insistentemente aos seus aspirantes a ator a importância do desenvolvimento da voz para a prática teatral e, em seu sistema possuía uma série de exercícios para o aprimoramento constante e sistemático dessa habilidade. Os exercícios envolviam práticas que trabalhavam a dicção, o canto, entonações, pausas e o uso correto dos acentos na linguagem oral. $\mathrm{O}$ autor estudou as regras dos acentos lógicos, as pausas, as entonações, e agregou todo esse conhecimento ao seu programa de formação do ator. Em seu sistema, ele estabeleceu como prioridade a expressividade na maneira de falar, o princípio da ação verbal dinâmica e constituída de um propósito, ou seja, ele sublinhou a importância da palavra para estabelecer as imagens da visão interior. Nas suas aulas, ele utilizava muitos recursos performáticos orais para ajudar os seus alunos a desenvolverem as habilidades orais como, por exemplo, na aula em que na figura do diretor Tórtsov, ele narra algumas experiências pessoais. Ele diz:

[...] quando eu recitava para mim mesmo, eu tentava falar com a máxima simplicidade possível, sem efeitos tonais insinceros, nem ênfase exagerada no verso. Procurava ater-me ao cerne do poema. A impressão que isso produzia devia-se ao fato de que as palavras das frases vibravam, cantavam e isso dava nobreza e uma qualidade musical à minha fala. Quando levei para o palco esse modo de falar, os atores, meus colegas, se espantaram com a mudança que ocorrera em minha voz, minha dicção e meu novo modo de exprimir sentimentos e pensamentos. Depois verifiquei que não tinha ainda resolvido todos os ângulos do problema. - Não basta que o próprio ator sinta prazer com o som de sua fala, ele deve também tornar possível ao público presente no teatro ouvir e compreender o que quer que mereça a sua atenção. As palavras e a entonação das palavras devem chegar aos seus ouvidos sem esforço. Isso requer muita habilidade. Quando a adquiri, compreendi o que chamamos a sensação da palavra. (STANISLAVSKI,2001, p. 127-128)

Assim, como professor/diretor, ele ensina que "[...]o artista deve cultivar a voz e o corpo sobre a base da mesma natureza. Se não seguem essa indicação, o aparato corporal da personificação resultará demasiado pobre para o delicado trabalho que lhe foi designado" (STANISLAVSKI, 1997, p. 31). O autor utiliza ainda a seguinte imagem para traduzir a importância da voz: 
Imaginem a um mudo que quer expressar os sentimentos ternos e poéticos que lhes inspiram a mulher amada, mas que em vez da voz só produz desagradável chiado. Deforma a bela emoção que sente em seu interior, a quem lhe é tão querida. Essa deformação o desespera. O mesmo ocorre com o artista, que sabe interpretar bem, mas cujas condições vocais são deficientes. (STANISLAVSKI, 1997, p. 61)

Grotowski (2002), outro grande diretor e mestre da Pedagogia Teatral, defendia que o ator deve exercitar constantemente o aparato vocal para evitar tensões musculares. "Deve aprender a controlar a sua própria voz, ouvindo-a, procurando fazer uma investigação individual, buscando determinar que imagens e associações se produzem durante os exercícios" (GROTOWSKI, 2002, p. 131).

Segundo Grotowski (2002), o ator devia buscar sempre conseguir reações vocais espontâneas e não somente aquelas que estão friamente calculadas. Também alertava para o problema daquele que possui algum defeito vocal que não possa ser erradicado, em lugar de escondê-lo, devia explorá-lo de diferentes maneiras, de acordo com os papéis que desempenha.

Num caminho semelhante, pode-se pensar a voz a partir da perspectiva de Zumthor (1993), ou seja, da sua possibilidade performática, como uma ação que transforma aquele que a pronuncia, tanto quanto aquele que é co-presente ao ato performático.

Assim, para compreender o significado da voz no trabalho do ator, é preciso pensá-la, no que ela pode proporcionar de significância, não pelo que é dito, mas justamente por aquilo que é expresso por um todo corporal. Trata-se daquilo que vai além da expressão, que transcende a simples transmissão de significados. Isso implica pensar na voz do ator, não apenas como expressão, mas como lugar e potência do acontecimento corporal e vocal.

Assim, a voz é central como conteúdo a ser ensinado nas aulas de teatro e, também, como meio pelo qual isso é ensinado. Em função dessa importância, a voz tornou-se objeto discursivo na Pedagogia Teatral, pois falar sobre ensinar e aprender teatro tem relação direta com a voz e a oralidade.

Nesse sentido, Melo (2011) analisou como os discursos do corpo e da saúde se configuram e entrelaçam no campo da Pedagogia Vocal do Ator. Ela sustenta que os enunciados expressos na Pedagogia Teatral, na medida em que afirmam "[...] a corporeidade da voz constituem o ator, sobretudo como sujeitos dos discursos da integralidade do ser, [...] da sabedoria do corpo, da autoria, da alteridade e da superação das dicotomias entre corpo-voz-mente-espírito" (MELO, 2011, p. 48).

Segundo Habeyche (2006), a voz é um instrumento único vinculado à identidade do indivíduo. "Ao mesmo tempo vozes são escolhas estéticas e políticas: teatrais. São signos. São concepções de sonoridades e veículos de visibilidade de ideias e emoções, pois o teatro é o lugar da visibilidade do humano" (HABEYCHE, 2006, p. 123). A autora defende que a voz teatral tem suas peculiaridades e objetivos, entretanto, 
para Habeyche (2006) cada ator é um sujeito único, com seu psiquismo, sua realidade corporal, sua disponibilidade e seus interesses, o qual deverá desenvolver diferentes possibilidades vocais, que serão desenvolvidas a partir de olhares e escutas dirigidas àquele sujeito individual. Ela defende que é possível provocar o aluno-ator a buscar a consciência do seu instrumento corporal e vocal através de leituras, de conversas, de exercícios para resgatarem fatos vocais nas suas memórias, utilizando todo o material disponível para o seu autoconhecimento e da sua voz. Desta forma, a autora defende que "[...] a comunicação está recheada de subjetividade. Todo discurso deseja agarrar seu interlocutor. Quando um ator trabalha a técnica, ele o faz imaginando. A imaginação é o poder implícito na técnica trabalhada" (2006, p. 60).

Habeyche (2006) considera que os alunos, ao saberem o que realizam vocalmente e como o fazem, apropriando-se de seu instrumento e das etapas que compõe o processo de criação vocal, podem fazer escolhas vocais ao criar personagens, colaborando para a construção da identidade fictícia com o seu trabalho vocal. O trabalho vocal deve ser entendido com e a partir da sua voz. Para a autora ao "[...] trabalhar com a subjetividade de imagens sugeridas ao coletivo, mas entendidas e percebidas individualmente, o aluno construirá seus próprios referenciais sonoro-imagéticos constituindo e sendo constituído pela sua subjetividade"(HABEYCHE, 2006, p. 123-124). Dessa forma, a autora defende que a comunicação está recheada de subjetividade.

Outra dimensão da voz, para além da expressão, seria pensá-la como poiética de si mesma, como forma constituição do próprio aluno ator em formação. É possível relacionar essa ideia como os ensinamentos de Tortsóv aos seus alunos/atores, pois, segundo ele,

[...] a fala é música. O texto de uma personagem ou uma peça é uma melodia, uma ópera ou uma sinfonia. A pronunciação no palco é uma arte tão difícil como cantar, exige treino e uma técnica clamando pela virtuosidade. Quando um ator de voz bem trabalhada e excelente técnica vocal diz as palavras de sua personagem, sou transportado por sua suprema arte. Se ele for rítmico, sou involuntariamente envolvido pelo ritmo e tom de sua fala, ela me comove. Se ele próprio penetra fundo na alma das palavras de sua personagem, carrega-me com ele aos lugares secretos da composição do dramaturgo, bem como aos de sua própria alma. Quando um ator acrescenta o vívido ornamento do som á aquele conteúdo vivo das palavras, faz-me vislumbrar com uma visão interior as imagens que amoldou com sua própria imaginação criadora. (STANISLAVSKI, 2001, p. 128)

Desse modo, podemos falar de uma voz que é constituída da junção de um trabalho técnico e de uma construção interna, a qual possibilita a expressão diferenciada no acontecimento teatral. Tratar-se-ia de expressar, mas também de pulsar, abrigar, acolher, criar.

Para compreender a dimensão poética e poiética da voz no trabalho do ator, podemos lembrar o trabalho de Sara Lopes (2005), para quem a voz pode ser obra de arte, a qual se articula na ideia de uma voz que pode fazer aflorar a constituição de um ator, desde que ele adote uma conduta ética, que se traduz no próprio processo do fazer 
teatral e na conduta criativa. Para Lopes (2005), compreender a voz como objeto de arte implica compreender suas funções como material da linguagem da representação teatral, na sua função poética, o que para a autora, se refere ao uso da voz que transcende o cotidiano, ou seja, à transmissão de ideias ligadas ao significado das palavras. Ao que parece, essa dimensão extra cotidiana da voz é o que Baumann (1984) diz da performance da oralidade, em que a comunicação é operada fora do conteúdo referencial.

A partir das posições dos autores que enaltecem o papel da performance da oralidade no trabalho teatral, uma questão se impõe: de que forma a performance oral se apresenta nas práticas docentes em teatro?

\section{A performance da oralidade como instrumento da prática docente}

As performances orais se configuram em situações em que as palavras são, em alguns momentos, “[...] proferidas performaticamente, algumas vezes objetivando hiperdimensioná-las, em outras, reconfigurando-as, mas sempre performatizando-as. Seria [...] aperformance como algo na linguagem que expande a linguagem" (PEREIRA, 2010, p. 141). Assim, Zumthor (2007) defende que "[...] a performance e o conhecimento daquilo que se transmite estão ligados naquilo que a natureza da performance afeta o que é conhecido" (2007, p. 32).

Conte e Pereira (2013), por sua vez, consideram que a performance imprime nas palavras uma grande expressividade, porque é um modo vivo de comunicação, uma vez que "[...] a voz, que nela se insere tem um caráter concreto e sensível, sendo um processo contínuo, único, móvel e efêmero de atualização incessante, que é próprio ao agir do professor" (CONTE; PEREIRA, 2013, p. 97).

Nas suas performances, além das palavras com um tom enfático, os professores corporalmente expressam ideias e sensações, usando diferentes entonações e empregando expressões faciais diversas. Nesta perspectiva, Zumthor aponta que "[...] na performance o uso da palavra é uma 'realização poética plena', um 'ato' em que se integram elementos visuais, auditivos e táteis que constituem a presença de um corpo e as circunstâncias nas quais ele existe" (ZUMTHOR, 2007, p. 69). Dessa forma, pensamos o trabalho pedagógico do professor a partir do uso de todas as habilidades que dispõem para envolver os alunos na problemática que exige a implicação de todos.

Efetivamente, na Pedagogia Teatral existe todo um trabalho voltado para o desenvolvimento da voz, tendo como foco o trabalho do ator. Trata-se de práticas que utilizam o texto, a palavra, o canto, as quais são objeto da formação em teatro.

Os professores propõem aos alunos exercícios vocais, mas usam a sua própria voz para realizar a oralidade que ensinam. A performance oral do professor, sempre atrelada a própria corporeidade, ajuda a incorporar personagens e a transportar os alunos ficticiamente para outro lugar. O professor de teatro, muitas vezes, incorpora diferentes personagens como recurso pedagógico ${ }^{2}$ e a sua performance oral é um dos centros dessa personificação. Ele, eventualmente, pode performar diferentes papéis como para demonstrar as várias possibilidades de improvisar com a voz a partir de um mesmo tema. 
A performance transposta (Pereira, 2010) numa espécie de ritualização da fala, num procedimento de se pôr da palavra; coopera para o estabelecimento de uma atmosfera, de um clima, de uma tonalidade afetiva, "[...] uma stimmung que hiperdimensiona a própria palavra e os sentidos por elas ventilados, sentidos esses que dinamitam, por fim, a pretensão cognitiva de encapsular o todo da experiência num conceito em particular" (PEREIRA, 2010, p. 145). De acordo com Pereira, "[...] performar a palavra significa, portanto, poetizá-la" (PEREIRA, 2010, p. 147).

$\mathrm{Na}$ oralidade do professor, o uso vocal pode aparecer como uma poetização da palavra cotidiana, a qual se transforma a partir do ato performativo. Ou seja, os professores transformam a palavra do cotidiano, perfomando-a, com a finalidade de marcar o seu significado. Da mesma forma que o professor faz uso de tal recurso, ele dedica grande energia para que seus alunos possam desenvolver essa habilidade em aula, explorando as várias possibilidades, a partir dos jogos de improvisação.

Nesse processo de poetização, a metáfora ou o uso das imagens, tem papel preponderante. A explicação de determinadas técnicas ou a explanação de alguns conteúdos, muitas vezes, se dão por intermédio da vivificação narrativa de alguma metáfora. O diretor Tórtsov, de certa forma, faz uma poetização da palavra, utilizando uma metáfora para descrever como vê a utilização da voz no fazer teatral, professando aos seus aspirantes a atores, que quando o ator

[...] controla seus movimentos e lhes acrescenta palavras a voz, parece-me que isto se torna um harmonioso acompanhamento para um lindo cantar. Uma boa voz de um homem quando entra em cena é como um oboé. Uma voz feminina pura e alta faz-me pensar num violino ou numa flauta. As profundas notas de peito de uma atriz dramática, lembram a introdução de uma viola.O baixo pesado de um pai nobre ressoa como um fagote, a voz de um vilão é um trombone, que troveja, mas também gargareja por dentro, de raiva ou pela saliva acumulada. Como os artistas podem deixar de perceber toda uma orquestra numa única frase, até mesmo numa frase simples, de sete palavras, como por exemplo, "Volte! Eu não posso viver sem você!” De quantos modos diferentes essa frase pode ser cantada e cada vez de um novo jeito! Quanta variedade de sentidos podemos atribuir-lhe! Que quantidades de estado de espírito! Experimente trocar o lugar das pausas e das acentuaçõese conseguirá um número cada vez maior de significações. Paradas curtas, combinadas com acentuações, destacam nitidamente a palavra-chave e a apresenta diferente das outras. Pausas maiores, sem sons, permitem impregnar as palavras com um novo conteúdo interior. Isto tudo é auxiliado pelos movimentos, pela expressão facial e pela entonação. Essas mudanças produzem estados de espírito renovados, dão novo conteúdo a toda uma frase. (STANISLAVSKI, 2001, p. 129)

$\mathrm{Na}$ fala de Stanislavski, quando incorpora o diretor Tórtsov, percebe-se a ênfase dada a oralidade na sua pedagogia. $\mathrm{O}$ autor orienta seus alunos atores de forma extremamente didática sobre as diversas formas de exercitar a expressão oral para uma boa atuação, lhes oferecendo diferentes caminhos para isso. Entretanto, o faz não como a expressão ou a demonstração de um conteúdo, mas o faz poetizando como ato a própria experiência pedagógica que acontece no momento em que fala. 
Tais professores (de teatro) lançam mão de suas habilidades artísticas, daquilo que aprenderam no exercício como atores. É visível, para quem observava de fora, que para que os alunos compreendam o que está sendo professado, lançam mãode conhecimentos de ator, incorporados no próprio corpo do professor: as expressões faciais e as entonações da voz, por exemplo. Assim, a performance da oralidade docente envolve a voz de maneira íntegra com o corpo, pois “[...] sem o corpo a voz não é nada. A voz por onde a poesia transita, aceita, assume a servidão que constitui a experiência do corpo, com tudo o que esse corpo implica, suas fraquezas e suas forças" (ZUMTHOR, 2005, p. 89).

Trata-se de uma potência pulsante no corpo. O trabalho docente de professores de teatro exige uma entrega dos corpos ao ato pedagógico, pois isso implica “[...] performar a palavra, para reconduzir o ouvido à voz; para restabelecer a memória da voz. Performar a palavra para captar a lateralidade, o fundamento.[...] Performar a palavra para professar" (PEREIRA, 2010, p. 152).

Professores de teatro usam a presentificação do próprio corpo e a materialidade da voz, a entonação, que muitas vezes soa grave ou mais aguda, o ritmo, as ações vocais, aparentemente com o objetivo de demonstrar como isso se faz em teatro; mas transcendem esse objetivo em seus próprios corpos, fazendo - para além da expressão - com que eles próprios sejam a experiência da oralidade viva.

Assim, o corpo do professor, bem como a voz, são instrumentos voltados a potencializar os sentidos dos alunos para dar conta da tarefa pedagógica, que tem a finalidade expressa de provocar nos alunos um estado de disponibilidade que possa desencadear a instalação de um canal que resulte na criação. Os propósitos da pedagogia do teatro revelam que "[...] a arte, sob o modo de sua transmissão, a performance - necessariamente poiética - nos fornece: a forma como forma potencial, histórica e cultural, em desenvolvimento, e a comunicação como forma material" (PEREIRA, 2010, p. 141). Aperformance se impõe com a intenção de provocar o desenvolvimento e a transformação.

Nessa perspectiva, Conte e Pereira (2013) propõem pensar a performance do professor não como um ato solitário, mas como uma prática que incide necessariamente sobre o real e, ao mesmo tempo, um movimento no qual entra-se no exercício da linguagem, numa formação que se constrói na interação com os outros atores. Eles defendem que "[...] a dimensão performativa abre possibilidades ao agir do ator/professor que assegura a identidade dos sujeitos e o poder de tomar uma iniciativa e fazer algo de imprevisto no mundo vital intersubjetivamente compartilhado" (CONTE; PEREIRA, 2013, p. 110). A performance oral é, portanto, a corporificação da palavra.

Desse modo, Pereira (2010) sugere que o ato pedagógico tem que ser pensado como um ato pleno de significado, no qual seja induzida uma transformação. Essa mudança é provocada por um uso particular do corpo e da palavra, por intermédio do qual os sujeitos do processo assumem diferentes papéis, que se modificam a cada instante. Aqueles que aprendem, também ensinam, do que se pode deduzir que o ato pedagógico implica não apenas uma entrega, mas um entregar-se a partir de sensações 
corporais, de modo que a aprendizagem se dá nessa interação. "Corpos que além do disciplinamento característico de nossos modos de subjetivação, lançam-se como performances em direção a alteridade, formam-se como ato performático, na comunicação, na tentativa de transformar e instaurar uma nova ordem"(PEREIRA, 2010, p. 53).

A performance da oralidade docente, para os professores de teatro, se confunde e se mescla com sua própria experiência artístico-formativa. Trata-se de poetizar as habilidades artísticas para convertê-las em propriedades pedagógicas. Qual didática não se beneficiaria de tal empresa?

\section{Referências}

BAUMAN, R. Verbal art as performance.Illinois: Long Grove,1984.

CONTE, E. PEREIRA, Marcelo de Andrade. Pedagogia da perormance: da arte da linguagem à linguagem da arte. In: PEREIRA, M. de A. (Org.). Performance e educação: (des) terriorializações pedagógicas.Santa Maria: Ed. da UFSM, 2013, p. 95-114.

FORTUNA, M. A performance da oralidade teatral. São Paulo: Annablume, 2000.

GROTOWSKI, J. Hacia um teatro pobre. Cidade do México: SigloVeintiuno. s.a. de c. v. Mexico, D. F. 2002.

HABEYCHE, G. C. Considerações sobre banquete de imagens: a complexidade do instrumento vocal. Anais do IV Congresso de Pesquisa e Pós-Graduação em Artes Cênicas. Rio de Janeiro, 2006.

ICLE, G. ALCÂNTARA, C. Teatro, Palavra, Performance: pensar a voz para além da expressão. Repertório, Salvador, n. 17, p. 129-135, 2012. Disponível em: <http://www.portalseer.ufba.br/ index.php/revteatro/article/view/5733/4275 >. Acesso: 25 jun. 2013.

LOPES, S. P. A voz em sua função poética. Cadernos da Pós-Graduação. Instituto de Artes/ UNICAMP, Ano7, v. 7, n. 1, 2005.

MELO, L. C. de. A voz como revelação do corpo: saúde e verdade na pedagogia vocal do ator. Dissertação de Mestrado. Universidade Federal do Rio Grande do Sul-UFRGS -RS. 2011.

PEREIRA, M. A. Pedagogia da performance: do uso poético da palavra na prática educativa Educação e Realidade. Porto Alegre, UFRGS, v. 35, n. 2. (maio/ago. 2010), p.139-155.

STANISLAVSKI, K. El trabajodelactor sobre si mismo em el procesocreador de la encarnación. Buenos Aires: Quetzal, 1997.

STANISLAVSKI, K. Ética y disciplina: método de acciones físicas. Seleccion y notas: Edgar Ceballos. México/USA: Editorial Gaceta. 2001.

ZUMTHOR, P. A letra e a voz. São Paulo: Companhia das Letras, 1993.

Introdução à poesia oral. São Paulo: Hucitec, 1997.

. Performance, recepção e leitura. São Paulo: Cosac \& Naify, 2007. 


\section{Notas}

${ }^{1}$ Tomamos o termo "docência performática" para marcar as ações vocais e corporais dos professores durante seus atos pedagógicos. Não se trata, por tanto, de uma atuação teatralizada, mas de uma operação ordinária, por intermédio da qual o professor usa seus corpo e sua voz para "atingir" os alunos.

${ }^{2}$ Sobre esse assunto ver a comunicação de pesquisa DAL BELLO, Márcia Pessoa; ICLE, Gilberto. Pode o professor ser um performer? Anais da 36a Reunião Nacional da ANPED. Goiânia-GO, 2013.

* Professor doutor da Universidade Federal do Rio Grande do Sul, Porto Alegre, Rio Grande do Sul - Brasil

** Doutora em Educação pela Universidade Federal do Rio Grande do Sul, Porto Alegre, Rio Grande do Sul, Brasil.

\section{Correspondência}

Gilberto Icle - Universidade Federal do Rio Grande do Sul, Faculdade de Educação, Departamento de Ensino e Currículo. Rua Paulo Gama s/n - prédio 12201 FACED sala 700-2, Farroupilha, CEP: 90046900 - Porto Alegre, Rio Grande do Sul - Brasil.

E-mail: gilbertoicle@gmail.com - marciampdb@gmail.com

Recebido em 21 de maio de 2014

Aprovado em 04 de julho de 2014 